\title{
Indian Pediatrics and Child Health in India
}

\author{
SANTOSh K BhargaVA \\ Editor, Indian Pediatrics (April 1980-1984) \\ Correspondence to: D-7, Gulmohar Park, New Delhi 110049.
}

The decade of 1980 was perhaps one of the most crucial period for Child Health in India. It is during this decade that child health issues, child health problems and child health policies were identified, recognized and announced by the Government of India. I took over as Editor of Indian Pediatrics in 1980 with a relatively young committee that included Dr. Subhash C Arya, Publication Secretary, Dr RN Srivastava, Secretary of the Committee, Dr DK Guha and Late Dr Man Mohan as Assistant Editors, and Dr Sudershan Kumari, Dr VP Choudhary, Dr SK Mittal, Dr I Narayanan, Dr UB Lall and Dr SN Lohe as Ex-officio members. The composition of the team reflected my strong feeling that the journal needed a committed dynamic team who could devote their time, energy and ideas to taking it forward.

\section{Changes Initiated By the Journal CommitTeE}

The first few years were very challenging as the Journal committee had to deal with several issues relating to the management, publication and submissions of articles by fellow members. There was a severe financial constraint and the journal was behind schedule by several months (had a large backlog of accepted manuscripts), and was not indexed or included in any citation index. The Journal Committee decided to be pragmatic and positive in decision making, defining its priorities in publishing original research from India concerning child health and focusing on advocating national policies and increasing the revenue for the journal.

There was a also a change in the outlay, the style and the cover page, printing and publication style of the Journal. All unpublished articles were referred back to the authors for updating them as some of these were lying unpublished for a long time. Publication backlog was cleared by publishing two issues every month. Financial status was improved by active fund raising through donations, increasing advertisements and claiming arrears for member's contribution from Indian Academy of Pediatrics (IAP) Central Office. A leading pediatrician of the time summed up the quality of the Journal by expressing "I look forward to receiving two national publications every month - one the India Today - a leading national weekly news publication and the other Indian Pediatrics".

\section{Priorities for Publication}

The first task was to adopt the Vancouver style of publication [1] which was already accepted by a group of Medical Journals in 1978. This needed special attention and focus because members were used to sending articles in a different format.

In the decade of seventies and in particular from 1978, Primary Health Care became a subject of international and national area of interest. Priority was accorded to articles related to preventable diseases such as, Diphtheria, Tetanus, Poliomyelitis, Typhoid fever, Measles, Tuberculosis and so forth which were published for their clinical spectrum, diagnostic methods and more importantly on research to see the effect of vaccination by observing the seroconversions of the various vaccines used at that time.

Malnutrition and micronutrients had continued to engage investigators. The journal published several articles on these and focused on diagnosis of undernutrition at the community level where the child could not even be weighed [3]. Diarrhea and dehydration continued to remain a major cause of childhood morbidity and mortality. The journal published several articles on oral rehydration, so as to sensitize the pediatric community on this major theme [4-5].

Mentally challenged, physically disabled and physical and mentally handicapped children had drawn particular attention of the members due to continued indifference and neglect by health planners, community and care givers. The Journal published articles including plea for legislation for mentally handicapped by Sinclair [6].This did find its impact in many legislations being enacted in later years [7].

To focus attention on the unacceptably high and almost static infant and childhood mortality in the country, the journal published editorials, lead articles, and research work focusing on neonatal mortality and neglect of newborn [8]. This perhaps led many leading pediatricians and activist to hold the first convention on newborn care and related problems in New Delhi in 1980 and made recommendation which were published by the journal [9]. The convention led to the foundation of National Neonatology Forum (NNF). The Journal 
published the first ever recommendations of the Government of India of a national workshop by the Ministry of Health and Family Welfare on "Minimum Perinatal Care" [10].

Jacob John proposed a National policy for control of Poliomyelitis in India which was published in the Journal [11]. This was later to become the corner stone for eradication of Poliomyelitis program in India. At this time the Journal was beginning to be recognized internationally. It began receiving international research publications which were duly published.

During this period, the number of pages in letters to editor's column was increased as members had become very interactive and it had become a favored column. Sensing the mood and desire of members, the journal published series of articles and editorials on pediatric sub-specialties such as hematology, oncology, pharmacology, cardiology, endocrinology and nephrology [12-17].

An interesting and significant article on reference for childhood growth monitoring from birth to 14 years was published by Datta Banik [18]. We had now established firm routines for the Journal publication and related concerns and felt the need to promote research in the country. It therefore focused on priority publication of 'Research and research methods' to stimulate interest and sensitize the members to the current research and future needs [19]. A landmark publication in 1982 was the proceedings of the "Workshop on Indian Childhood Cirrhosis" which strongly made a persuasive case for excessive deposit of copper in the liver as a causative / precipitating factor in Indian childhood cirrhosis [20].

In the years 1983-84, thyroid and trace elements deficiencies became a hot area for investigations. Articles were published on prevalence of iodine deficiency, goiter and drugs for its treatment [16]. The researchers focused on deficiency of thyroid in newborn period and recommended routine screening at birth which has now become part of routine neonatal screening program. During this period, the government announced "Indian National Code for protection and promotion of breast feeding" and its recommendations were published in the journal [21].

The Journal traditionally published a Presidential address every year. Interestingly, almost all the Presidential addresses emphasized delivery of health care, pediatric education, research and people's (community) involvement. But an unusual and very illustrative address of current status of child health in India was delivered by Prof. BNS Walia at the National
Conference of Pediatrics in Pune [22]. The Journal published a timely review as an editorial on 7th plan by Prof Walia and subsequently other related articles on planning which pointedly drew attention to the lacunae in provisions for child health in earlier and 7th National Five year plans and also published his suggestions for the 7th five year plan [23]. These publications strongly recommended measures for setting goals and funds for meeting the preventive and curative needs for children of the country.

The incessant efforts and perseverance of proactive advocacy by the members of IAP across the country and their views and efforts expressed through their publications in the journal caused the government to do a re-think on its child health policies and priorities. These had immediate as well as long term impact in formulation of National Child health programs in successive years the National Policy on Health setting national goals on Maternal and Child Health indicators to be achieved by 2000 AD; legislation on Mental Health, Rehabilitation, Persons with disabilities; Indian National Code for protection and promotion of breast feeding and others.

Acknowledgments: It is very difficult to express my gratitude and appreciation to the contributors, members of the Journal committee, readers, my peers, colleagues, friends and advertisers who supported the journal during its difficult period and later. Nevertheless, I would like to specially mention the constant help and support from Prof. R.N. Srivastava, Dr Subhash C Arya, late Dr. Man Mohan and Dr. U.B. Lall; my teachers late Dr. J.N. Pohowalla, late Dr. P.N. Taneja and my mentor Dr. Shanti Ghosh whose teaching, philosophy and commitment to maternal and child health, for national issues, national concerns, research and specially to reach colleagues in community shaped several of my policies and priorities while leading the journal committee. I also deeply appreciate the critical comments and support from Dr. B.N.S. Walia, Dr. A.B. Desai, Dr. D.G. Benakappa, Dr. K.K. Kaul, Dr. N.R. Bhandari, Late Dr S.M. Merchant, Late Dr J.R. Srivastava, Late Dr R.S.Dayal, Late Dr O.P.Ghai and others. I am grateful to my former colleagues at Safdarjang Hospital, Dr. H.P.S. Sachdev, Dr. S. Ramji, Ms. Madhuri Gupta, staff of the journal Mr. O.P. Assija, Mr.Sant Lal, late Mr.Puran Giri, the publisher of the Journal Mr Rajesh Sardana and Mr Bhaskar Singh from the New Delhi Birth Cohort for his help and research for this publication.

\section{REFERENCES}

1. Srivastava RN. Indian Pediatrics: style and content. Indian Pediatr.1980;17:399.

2. Government of India, National Rural Health Mission: Mission Document. New Delhi: MOHFW; 2005.

3. Mohan M, Ghosh S, Ramanujacharyulu. Assessment of malnutrition by mid arm circumference and its ratio to head circumference. Indian Pediatr.1980;17:503-6.

4. Ghai OP, Bhan MK. Complications of commercial rehydration packets. Indian Pediatr.1984;21:591-3. 
5. Sachdev HPS, Bhargava SK, Gupta BD, Narula S, Daral TS, Mohan M. Oral rehydration of neonates and young infants with dehydrating diarrhea. Indian Pediatr.1984;21:195-9.

6. Sinclair S. Legislation for the mentally handicapped. Indian Pediatr.1981;18:19-21.

7. Mental Health Act, 1987. Bare act with short comments; Commercial Law Publishers, Delhi, 2007.

8. Bhargava SK. Neonatal care: a newborn's right and not a luxury. Indian Pediatr.1981;18:687-90.

9. Bhakoo ON. Announcement: National Neonatology Forum. Indian Pediatr.1980;17:639.

10. Bhargava SK. Regional perinatal care - paediatric aspects. Indian Pediatr.1982;19:291-8.

11. Jacob John T. Towards a national policy on poliomyelitis. Indian Pediatr.1981;18:503-6.

12. Bhargava M. Pediatric haematology: A neglected speciality. Indian Pediatr.1982;19:467-8.

13. Gandhi RK. Cancer in childhood-Need for a planned approach. Indian Pediatr.1981;18:363-4.
14. Mehta S. Developmental pharmacology. Indian Pediatr.1982;19:391-2.

15. Sanyal SK. Non-invasive evaluation of the heart in children: state of the art. Indian Pediatr.1982;19:3-5.

16. Desai MP. The Rationale of levothyroxine therapy in hypothyroidism. Indian Pediatr.1983;20;3-4.

17. Srivastava RN. The challenge of irreversible renal failure in children. Indian Pediatr.1983;20:79-81.

18. Datta Banik ND. Semi-longitudinal growth evaluation of children from birth to 14 years in different socio-economic groups. Indian Pediatr 1982; 19: 353-9.

19. Merchant SM. The research priorities. Indian Pediatr. 1982;19:199-200.

20. Bhargava SK. Indian childhood cirrhosis. Indian Pediatr.1982;19:961-2.

21. Indian National Code for Protection and Promotion of Breast-feeding. Indian Pediatr. 1984;21:259-64.

22. Walia BNS. XX National Conference of Indian Academy of Pediatrics. Indian Pediatr. 1983;20:885-91.

23. Walia BNS. Child health in the $7^{\text {th }}$ Plan 1985-90, India. Indian Pediatr.1983;20:631-5.

\title{
Challenging Days
}

\author{
RN SRIVASTAVA \\ Editor, Indian Pediatrics (1985-February 1990) \\ Correspondence to: Consultant, Indraprastha Apollo Hospital,New Delhi, India.drrnsri@gmail.com
}

I was appointed Editor of Indian Pediatrics in 1985 by the IAP Executive Board. Before that too, I was closely involved with the scientific aspects of the Journal when Dr SK Bhargava took over as the Editor. He found an excellent, dependable publishing house, Cambridge Press, who have printed the Journal and several other publications for us for over 40 years. The regularity of publication of the Journal has been most remarkable.

I had a strong supporting team constituting the Journal Committee. We focused on the quality of the journal, selecting the articles for publication strictly based on their scientific merit. Preparation of manuscripts according to Vancouver style (rather than "free style", which required great deal of editing) was insisted upon. Our readers were exhorted to submit their outstanding wok to the Journal, which alone would enhance its quality. The contents as well as their presentation were closely scrutinized [1].

The major constraints were financial. The earnings from advertisements were insufficient and moreover, we had to be selective in accepting these. It was, however, emphasized that information about any product should not be regarded as its promotion.

In 1985 the Journal brought out a supplement "Emergencies in Pediatrics", which was sold by us directly with all profits going to the Journal [2]. Subsequently, a book entitled "Pediatric and Neonatal Emergencies" was published by our own publishers and again profits from its sale were used towards journal expenses [3].

The Journal celebrated its silver jubilee in 1988. A special number was printed, which included a few Abstracts of outstanding articles published earlier in the Journal [4]. The IAP membership (to whom the Journal was being sent as part of their lifetime subscription) had reached 4200 !

The Journal had been housed in the departmental offices of the Editor. Limitation of physical facilities had created increasing hardship. Although makeshift arrangements were eventually made, there remained an urgent need for adequate premises that must include a library and seminar rooms.

I have observed with great satisfaction the progress 